Journal of Innate

Immunity
J Innate Immun 2009;1:291-300

DOI: $\underline{10.1159 / 000211193}$
Received: December 17, 2008

Accepted after revision: December 20, 2008

Published online: April 2, 2009

\title{
Evolution and Function of Innate Immune Receptors - Insights from Marine Invertebrates
}

\author{
Philip Rosenstiel $^{\mathrm{a}}$ Eva E.R. Philipp ${ }^{\mathrm{a}}$ Stefan Schreiber ${ }^{\mathrm{a}}$ Thomas C.G. Bosch \\ a Institute for Clinical Molecular Biology and ${ }^{b}$ Zoological Institute, Christian-Albrechts University Kiel, \\ Kiel, Germany
}

\section{Key Words}

Innate immunity · Sea urchin · Cnidaria ·

Nucleotide-binding and oligomerization domain-like receptor $\cdot$ Toll-like receptor $\cdot$ Crohn disease $\cdot$ Asthma

\begin{abstract}
Innate, nonadaptive immune receptors represent phylogenetically ancient first-line sensors of invariant non-self patterns and other cellular danger signals. From lower animal phyla to vertebrates, most pathogens are immediately detected by various recognition systems and are destroyed by induction of defense effectors like antimicrobial peptides. Toll-like receptors, nucleotide-binding and oligomerization domain-like receptors and scavenger receptor cysteine-rich proteins represent archetypes of the innate immune receptors, which mediate the complex interaction between the host and microbiota at the interface of epithelial barriers. In this review, we will use knowledge gained from marine invertebrates as a paradigm to describe how this constant molecular crosstalk within the holobiont, i.e. the animal with all its associated microorganisms, contributes to epithelial homeostasis, immunological integrity and maintenance of the resident microbial diversity.

Copyright $\odot 2009$ S. Karger AG, Basel
\end{abstract}

\section{Introduction}

Maintenance of the immunological integrity of organisms has been a driving force in evolution. Diversification of life forms has led to a vast number of heterogeneous non-self recognition strategies and defense effector mechanisms. However, selected principles of innate immunity seem to be molecularly conserved across animal phyla. These major functions of the innate immune system include a controlled host/microbial crosstalk at epithelial barriers, the recognition of danger signals, clearance of intracellular pathogens by autophagy, the recruitment of mesoderm-derived professional immune cells and the secretion of local or circulating effector molecules such as antimicrobial peptides and simple opsonic forms of complement.

In this review, we will discuss selected aspects of innate immune recognition strategies in marine invertebrates and demonstrate that this field is rapidly evolving by the advent of novel genomic techniques including ultrafast sequencing. Marine invertebrate species are especially suited to understand the evolutionary forces that shape genetic diversity of the innate immune armamentarium as they are constantly subjected to selective pressures from variable physical conditions of the aquatic habitat (e.g., light, salinity, dense microbial communities, trophic conditions). As some marine animals (e.g., the 
bivalve Arctica islandica) are among the longest living animals on earth, we will debate the role of immunosenescence and longevity. We will use this knowledge to show that innate immune mechanisms play a crucial role in the broadening concept of the 'holobiont'. This term, which was first coined in corals to describe the functional entity of the animals together with their respective endosymbionts and associated microbiota [1], emphasizes the role of an intact host-microbial interaction for normal development and function of epithelial barrier organs conserved from marine invertebrates to humans. The general importance of these principles also for human health has become increasingly clear, as it was demonstrated that genetic variants in phylogenetically ancient innate immune genes are involved in the etiology of emerging chronic inflammatory diseases of epithelial barrier organs such as Crohn disease, atopic dermatitis and asthma [2].

\section{Germline Genetic Diversity of Innate Immune Receptors: Toll-Like Receptors, Nucleotide-Binding and Oligomerization Domain-Like Receptors and Scavenger Receptor Cysteine-Rich Domain-Containing Proteins}

Conversely to the genetic plasticity of the adaptive immune system in vertebrates that allows maturation and selection of high-affinity responses towards a specific antigen, the innate immune system has its origin early in the evolution of metazoans and relies on a limited set of germline-encoded receptors for recognition of danger signals. These pattern recognition receptors (PRRs) sense invariant molecular signatures that are either present in potential pathogens (pathogen-associated molecular patterns, PAMPs, e.g., lipopolysaccharides or unmethylated CpG DNA) or that are derived from endogenous sources (e.g., extracellular heat shock proteins, oxidatively modified proteins) and attest profound cellular damage. Engagement of these receptors leads to a fast induction of protective programs, e.g., the induction of antimicrobial peptides or the elimination of the infected cell by means of apoptosis. Whereas the sets of innate immune receptors seem to be rather conserved, it must be emphasized that the molecular realization of protection downstream of receptor activation and their cognate pathways may vary considerably among phyla. Various families of conserved PRRs have been identified, which are either localized on the cellular surface or in intracellular compartments. In this review, we will focus on 3 major types of receptors. Toll-like receptors (TLRs), which belong to the Toll/IL1R receptor family, are a prototype of the transmembrane PRR with an extracellular ligand-binding domain and an intracellular adaptor domain, where downstream signaling molecules are recruited upon activation [3]. The intracellular nucleotide-binding and oligomerization domain (NOD)-like receptor (NLR) family plays a pivotal role in the recognition of intracellular PAMPs [4] and is related to the apoptosis-inducing apoptosisprotease activating factor (APAF)-like molecules. The third group is the family of scavenger receptor cysteinerich (SRCR) domain-containing proteins [5]. A complex set of transcripts featuring SRCR repeats can be found from sea urchins to humans, which may contribute to the diversity of innate immune responses.

\section{Toll-Like Receptors}

The domain architecture of TLRs comprises extracellular 15-25 leucine-rich repeats (LRRs), a transmembrane domain and an intracellular Toll/IL-1 receptor signal-mediating domain [3]. It is thought that the extracellular domain senses the signal which it transmits to the nucleus via a complicated pathway of adaptor molecules leading to an activation of the transcription factors nuclear factor- $\kappa \mathrm{B}(\mathrm{NF}-\kappa \mathrm{B})$ and different interferon-regulatory factors (fig. 1). This structure and cognate function is strikingly similar to functional homologs in plants [6] and has first been identified as an important receptor system in Drosophila dorsoventral patterning [7]. Since then, it has been recognized that besides this developmental role, which seems to be rather unique to insects, a major role of the ever-increasing family of TLRs is the recognition of immunological danger signals. Again, first clues were derived from the Drosophila model system [8] and were later extended to other phyla. The receptor system has been an archetype of our understanding of how invariant extracellular sensor structures may recognize threats induced by microbial assaults. Two main theories have been put forward. (1) The receptor directly binds to conserved minimal structures of pathogens. It was proposed by Janeway and Medzhitov [9] that the recognized PAMPs are so essential to survival and replication of the bacteria or other microbiota that they cannot be easily modified in order to escape immune recognition. This concept leaves us with the problem of how a pathogen can be distinguished from the abundance of commensals and symbionts, which are likely to harbor the same molecules (e.g., lipopolysaccharides, lipopeptides, certain nucleic acids) and, ultimately, with the unanswered question why a host that carries myriads of bacteria on its surfaces does 
not succumb to constantly high levels of inflammation. (2) The pathogen leads to an alteration or unmasking of hidden 'self' structures by cellular damage. Normally, these molecules, e.g., extracellular heat shock proteins released by lysed cells, are not seen by the TLR system. A theoretical advantage of this recognition strategy is that simple mutations in microbial genomes, which do not interfere with pathogenic virulence, may not easily lead to a direct evasion of recognition of cellular danger in itself.

Which traces of TLR pathways can be found in genomes of aquatic invertebrates and what can we learn about the early roots of TLRs in host defense?

Until a few years ago, the diversity of TLR genes throughout animal phyla seemed rather limited and TLRs were hypothesized to play a major role in mesodermal cells, i.e. fat body cells or circulating professional immune cells. Both views were undermined by genomic data from marine invertebrates. In the genome of the purple sea urchin, Strongylocentrotus purpuratus, more than 200 TLR gene models have been identified which can be classified into a number of distinct subgroups [10, 11]. This strikingly high diversity was in contrast to the narrow repertoire of the classical invertebrate model organisms Caenorhabditis elegans and Drosophila melanogaster and other marine invertebrates, e.g., the bivalve Chlamys farreri [12]. Work by Rast and colleagues has pointed out that TLRs in the sea urchin display characteristic features of a rapidly evolving gene family with more than $30 \%$ pseudogenes, tandem gene structures and a high rate of nonsynonymous polymorphisms especially in the LRR-containing ectodomain $[10,13,14]$. Interestingly, the majority of TLRs in S. purpuratus have a high homology to vertebrate-like TLRs, and only few genes display sequence similarity to protostome TLRs (e.g., Toll from $D$. melanogaster) pointing to an early bilaterian divergence of TLR subgroups [14]. Why has this expansion of TLR genes occurred in echinoderms? It is of course tempting to speculate that the genetic repertoire of receptors is reflecting the diversity of ligands, and thus threats, which can be recognized as danger signals. This could be interpreted as an evolutionary response to generate diversity and specificity of antigen sensing under the selection pressure by vast amounts of benthic microbes. However, this positive selection clearly is hypothetical and remains to be rigorously proven, e.g., by molecular identification of ligands activating specific TLRs and detailed phylogenetic analysis including population analysis of different sea urchin species and other echinoderms from different habitats.

Evolution and Function of Innate Immune Receptors

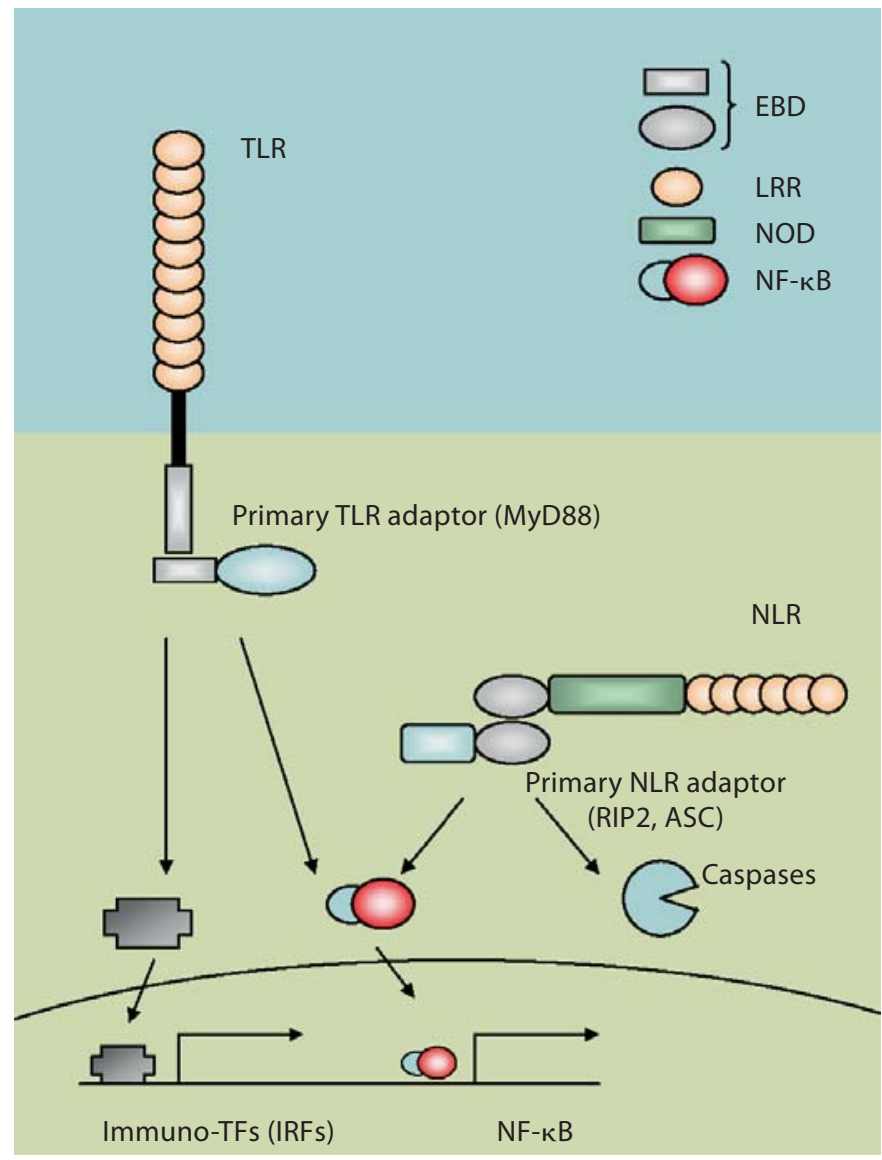

Fig. 1. Conserved principles of innate immune recognition: signaling pathways of TLRs and NLRs. TLR proteins are integral membrane proteins with an ectodomain comprised of LRRs and an intracellular Toll/IL-1 receptor signal-mediating domain as effector-binding domain (EBD). NLR proteins typically comprise 3 domains with a C-terminal ligand recognition domain consisting of LRRs, a central NOD and the N-terminal effector-binding domain, which can be realized as a DEATH, CARD (caspase recruitment) or PYD. Upon activation, the receptors recruit primary adaptor molecules to engage downstream signaling pathways including NF- $\kappa \mathrm{B}$, interferon-regulatory factors (IRFs) and caspases. RIP2 = Receptor interacting protein 2; ASC = apoptosis-associated speck-like protein containing a CARD; MyD88 = myeloid differentiation factor 88 ; TFs $=$ transcription factors .

In the sea urchin, expression of TLRs seems to be restricted to coelomocytes, i.e. to simple forms of professional immunocytes derived from the mesenchyme [10, 14]. Is the primordial migratory immune cell the origin of TLR pathways as a defense tool in animals? This perspective has been challenged by studies in early branching metazoans that lack the mesodermal layer (e.g., sponges, corals, sea anemones and polyps). Recent data point to a pivotal role for TLRs in epithelial immune de-

Innate Immun 2009;1:291-300 
fense in these animals. In the demosponge Suberites domuncula, a receptor with high homology to bilaterian TLRs and a cognate adaptor kinase similar to IL-1 receptor-associated kinase have been cloned [15] and demonstrate that the phylogenetically oldest extant metazoan phylum already comprises this important signaling pathway of the antimicrobial host defense system in the absence of a mesodermal layer. Unequivocal evidence for a functional TLR system in early eumetazoans has been gathered in Cnidaria. Data from expressed sequence tag archives have clearly shown the presence of several orthologs of TLR genes in the classes of Anthozoa and Hydrozoa $[16,17]$. Although in the genome of Hydra magnipapillata conventional TLRs are absent, TLR function is realized by the interaction of an LRR domain containing protein with a Toll/IL-1 receptor signal-mediating domain containing protein lacking LRRs. Coexpression of both membrane proteins is linked to antimicrobial peptide induction in vivo, and heterologous overexpression of the 2 Hydra proteins in mammalian cell lines leads to a sensitization to the PAMP flagellin supporting the hypothesis that the epithelium represents the ancient system of host defense [18].

\section{NOD-Like Receptors}

$N L R$ genes encode for cytosolic proteins that comprise a trimodular domain structure, characterized by a central NOD, and an N-terminal DEATH-fold-like effectorbinding domain, e.g., a Pyrin domain (PYD), DEATH or caspase recruitment domain (CARD) [4]. The NOD, also termed 'NACHT domain' (a domain present in neuronal apoptosis inhibitor protein, the major histocompatibility complex transactivator (CIITA), HET-E and TP1) [19], is a member of the recently defined superfamily of P-loop NTPases. Sequence homology exists with the nucleotidebinding core of APAF-1, which is responsible for the dATP/ATP-dependent oligomerization of APAF-1 upon cytochrome $\mathrm{c}$ recognition, which activates the initiator caspase-9. Upon ligand sensing via the C-terminal LRRs, which can be regarded as the intracellular counterpart of the ectodomain of the TLRs, the molecules have propensity to form self-oligomers, thereby recruiting proximityactivated binding partners (fig. 1). This leads to either activation of proinflammatory signaling pathways (e.g., NF- $\kappa \mathrm{B}$ transcription factor via canonical RIP2/IKK signals) $[20,21]$ or direct activation of proinflammatory caspases via formation of a large protein complex, which in turn enables the processing of IL-1 $\beta$-like substrates [19]. Here, the same question has been posed as with the TLRs: do NLR-type LRRs directly bind to their cognate PAMPs or are they indirect sensors of cellular danger? Whereas in TLRs there is evidence for the realization of both principles [22-26], in NLRs, the situation is less clear. Minimal structures from bacterial peptidoglycan have been shown to activate human NOD1- and NOD2-dependent signaling. Human NOD1 sensitizes cells to a unique diaminopimelate-containing $\mathrm{N}$-acetylglucosamine- $\mathrm{N}$-acetylmuramic acid (GlcNAc-MurNAc) tripeptide motif present in the peptidoglycan of Gram-negative bacilli [27, 28] and, particularly in Gram-positive bacteria, NOD2 detects the more generalized motif muramyl dipeptide (MurNAc-L-Ala-D-isoGln, MDP) [29, 30]; however, no convincing direct binding assays have so far been provided. For the inflammasome-forming NALP3, a variety of exogenous (e.g., asbestos, viral DNA and MDP) and endogenous danger signals (e.g., monosodium urate, ATP) have been identified as elicitor molecules [31-34]. Unifying principles how all these different compounds are integrated into a specific NALP3-inflammasome signal may involve the activation of potassium ion fluxes through P2X7-gated ion channels $[33,35]$ or sensing of reactive oxygen species [31] which are induced downstream of the aforementioned elicitors.

It must be emphasized that all of this knowledge has been gained from studies of vertebrate NLRs. Until a few years ago, NLR genes were thought to have evolved in teleost fish probably by means of domain shuffling [36, 37], as only single domains of NLR genes with low homology had been identified in the genomes of the classical invertebrate model organisms D. melanogaster, Ciona intestinalis and C. elegans.

The genome sequence of the purple sea urchin again revealed surprising evidence that $N L R$-like genes were already present in echinoderms. A multigene family of more than 200 NLR-like genes has been identified clustering into different subfamilies [10,14]. While in many of the gene models the exact structure of the C-terminal sensor region has not yet been convincingly elucidated, the $\mathrm{N}$-terminal effector-binding domain is realized as a DEATH domain, rather than as a CARD or PYD motif. It is hypothesized that all of these domains have evolved from a common DEATH-fold-like ancestor [38]. As the cognate adaptors in S. purpuratus (RIP2-like kinase and orthologs of proinflammatory caspases) also carry DEATH domains as homotypic interaction motifs, it will be interesting to reveal at which point of evolution the whole system has switched to a higher complexity of CARDs and PYDs as homotypic interactors.

In vertebrates, 2 major themes of NLR-mediated immunity have been proposed. (1) NLRs are involved in 
shaping immune responses induced by mesodermal professional immunocytes (e.g., dendritic cells and monocytes) [39-41]. It has been shown that NOD2 triggers a potent antigen-specific immune response with a Th2type polarization profile, demonstrated by the induction of IL- 4 and IL- 5 by T cells and IgG1 antibody responses. These findings together with other data pointing to a role of NLRs as negative regulators for Th1-type immune responses show that NLRs are involved as microbial-induced polarization principles and provide a link between the innate and the adaptive immune system. (2) The NLRs NOD1 and NOD2 have been shown to play a pivotal role in intestinal epithelial cells as a first line of immune defense [42-47]. Dysfunction of NOD2 has been associated with an impaired expression of antimicrobial peptides at the intestinal barrier [48-50]. In the sea urchin, the gut seems to be a major site of NLR expression [13], which may point to a primordial function of NLRs in protective epithelial responses and shaping of associated microbial communities. Thus, functional insights from lower invertebrates are urgently needed to understand the evolutionary origins of NLRs as epithelial sensors involved in the maintenance of commensal diversity and defense against pathogens.

\section{SRCR Domain-Containing Proteins}

SRCR-containing proteins constitute a group of conserved receptors playing a role in innate immunity and development. The SRCR domain is phylogenetically ancient and is defined through a cysteine-rich protein module of approximately 100-110 amino acids, which was first described as a scavenger receptor in macrophages [51]. SRCR proteins can be found throughout all animal phyla from poriferans to chordates. The SRCR motif in scavenger receptors expressed in mammalian macrophages provides direct binding to microbial motifs [52] and aberrant self such as altered lipid structures [5]. The role of other SRCR motif-bearing proteins is heterogeneous: while some genes encode classical type $1 \mathrm{mem}-$ brane proteins, others code for secretory proteins that may be involved in immune exclusion $[52,53]$. Multidomain SRCR proteins were shown to be an immensely large family in sea urchin coelomocytes, where they were shown to be regulated upon immune challenge $[11,14$, 54-56]. In the marine sponge Petrosia ficiformis, the SRCR gene PfSym 2 is differentially expressed in relation to its symbiotic state [57]. DMBT1, a protein structurally similar to the sea urchin multidomain SRCR factors, is linked with NLR and TLR signaling in vertebrates [53]. Deletion variants in the gene have been associated with epithelial cancers and inflammatory diseases, pointing to a crucial role in both epithelial defense mechanisms and proliferative homeostasis. Given the highly dynamic and variable expression patterns of multidomain SRCR transcripts in cell populations of the sea urchin, the family of proteins may serve as an interesting starting point to functionally dissect the evolution of the direct interaction between host and microbiota.

\section{Stable Host-Microbiota Interactions - Towards an Understanding of the Evolution of the Holobiont}

We are beginning to understand that the complex interaction between commensal communities of microbiota residing on the surfaces of epithelial barriers and their respective host is required for normal development, epithelial regeneration and maintenance of immunological integrity in general [58-60]. The microbial flora attached to epithelial interfaces plays an important role in nutrition physiology, and disturbed diversity of microbiota is associated with a wide range of pathologies from obesity to atherosclerosis to emerging chronic inflammatory diseases [61]. Body surfaces are colonized by microorganisms from their first days of life. This principle is true for all animal life forms, not only for mammals, where the maternal flora serves as the predominant source of initial colonization [62]. Most epithelial surfaces are covered by physical barrier substances, e.g., mucus or chitin. Character and composition of these layers are pivotal for the spatiotemporally controlled microbial colonization. It has been shown in a variety of species that despite a high degree of individual variation in microbiota composition over time, the core microbial communities remain highly stable and species specific. This argues for a strong host genetic control and coevolution of the host and its associated microflora $[58,62,63]$. The longitudinal variance of microbial diversity on interface organs during the entire lifespan and the passive modification of the flora by environmental influences, including nutrition and hygiene, are unclear [64]. Only few studies have focused on the 'resilience' phenomenon, i.e. the capacity of the microflora to regain homeostasis of diversity after environmental challenges such as infections. This phenomenon involves the process of 'quorum sensing', i.e. the communication between microorganisms by specific ligands such as homoserine lactones, but also the creation of ecological niches beneficial for the epithelial barrier and immune system of the host $[65,66]$. Vice versa, a requirement of tonic recognition of bacterial components 
through TLRs and NLRs seems to exist in order to create a normal regenerative capacity of the epithelium and to drive a normal development of underlying mesodermal immune cells. On the bacteria side, the Mazmanian group was first to reveal the identity of a molecular entity, polysaccharide $\mathrm{A}$, involved in this process in mice $[67,68]$. Interestingly, the symbiontic relationship between epithelial cells and microbes has been emphasized by several studies in marine invertebrates, where the recognition of tracheal cytotoxin from Vibrio fischeri is required for epithelial light organ formation in squids [6971]. Although the receptors involved in the recognition of $V$. fischeri have not been identified yet, it must be noted that tracheal cytotoxin represents the specific elicitor for the murine NLR NOD1 [72], making it tempting to speculate that innate immune signaling is involved. The role for epithelial homeostasis and proliferation is also supported by data from the basal eumetazoan Hydra viridis demonstrating that bacteria-derived factors are needed for proper budding. Aposymbiotic animals that do not reproduce asexually under sterile conditions regain their budding ability after addition of nonsterile Artemia larvae or bacteria per se [73].

From all the cumulated data on host-microbial interactions, a mutual dependency between host and associated microbiota can be hypothesized, in which the metabolic activities of the bacterial flora are responsible for gene regulation necessary for homeostasis of the host barriers [58]. This homeostasis and the gene expression programs specifically induced via innate immune receptors in turn stabilize the diversity of the associated microbiota. This principle of a 'holobiont' is conserved from humans to early branching eumetazoans [1]. Although the term was first used in corals to describe the complete animal with its endosymbionts and associated microbiota, we propose to broaden the holobiont concept, as the dynamic communities of microbiota on body surfaces must be understood as an integral part of the functionality of the respective organism itself, regardless of the animal phylum.

\section{A Role for the Innate Immune System as a Determinant of Longevity?}

For a long time the concept was iterated that evolution of the adaptive immune system as a more effective immune defense was needed to meet the requirements of the increasingly complex bauplan and a long life [9]. This would imply that animals with only the innate immune system at hand are simple and short lived. However, many marine invertebrates are extremely complex (e.g., the giant squid) and are record holders of longevity. Species of sea urchins and crustaceans show life spans of over 100 years (AnAge database) and, among bivalves, 2 species have been found that represent 2 of the longest lived animals on earth, thefreshwater pearl shellMargaritifera margaritifera (maximum life span potential 190 years) [74] and the marine mud clam $A$. islandica with a lifespan over 375 years $[75,76]$. Furthermore, sponges and the freshwater polyp Hydra are assumed to be nearly immortal. This demonstrates that also with an innate immune system, extrinsic mortality due to infections or cancer development are prevented and longevity can be achieved. Studies directly linking immune responses and longevity in such longlived invertebrates are still scarce and completely absent on a molecular basis. Whereas the genome sequence of the purple sea urchin may be used to extrapolate the diversity of the immune gene repertoire in longer-lived echinoderms, genomic data for bivalves are very limited. Interestingly, a high genetic variability has been shown in oysters [77] (approximately 1 single nucleotide polymorphism per $40 \mathrm{bp}$ ), which may contribute to plasticity of immune response in populations spread across different habitats with distinct selective pressures. One first line of evidence of how an effective program for tissue repair and defense against infection is associated with longevity in marine invertebrates has been demonstrated in the long-lived bivalve $M$. margaritifera. Ziuganov et al. [74] tested the regenerative capacity after experimental injury in populations displaying a different maximum lifespan. Individuals from a southern Spanish population reach 30-40 years, whereas specimens from the Arctic can live up to 200 years. Upon mutilation, it was found that the longer-lived arctic population showed higher shell and wound healing as well as survival rate compared with the shorter-lived population from Spain. On a population level, no diseases, parasites or tumors were observed, even in old individuals. Furthermore, the biological principle seems to be transmissible, as infestation of the Atlantic salmon Salmo salar with parasitic M. margarifitifera larvae, of the arctic population, which develop inside the fish gills, resulted in higher resistance of the fish to burns and wounds, prevention of cancer development and an increase in lifespan beyond the first spawning event after which the fish normally dies [74]. Although it must be pointed out that this observation is purely coincidental and may not be directly linked to the longevity principle of the bivalve in itself, the larvae can somehow 'switch off' the death program of the fish and enhance its stress resistance. 
Fig. 2. Scheme of important immune-related events during animal evolution. The phylogenetic tree represents model organisms where genomic and/or transcriptomic data are available. Note that the immune-related changes in genome architecture in the diagram represent the current knowledge. The advent of ultra-fast sequencing and other genomic tools allows for a fast and systematic exploration of additional model organisms which may result in a comprehensive view on the origins and distribution of the immune gene repertoire in the animal kingdom. VDJ = Variable (V), diversity (D) and joining (J) gene rearrangement for antigen receptor diversification.

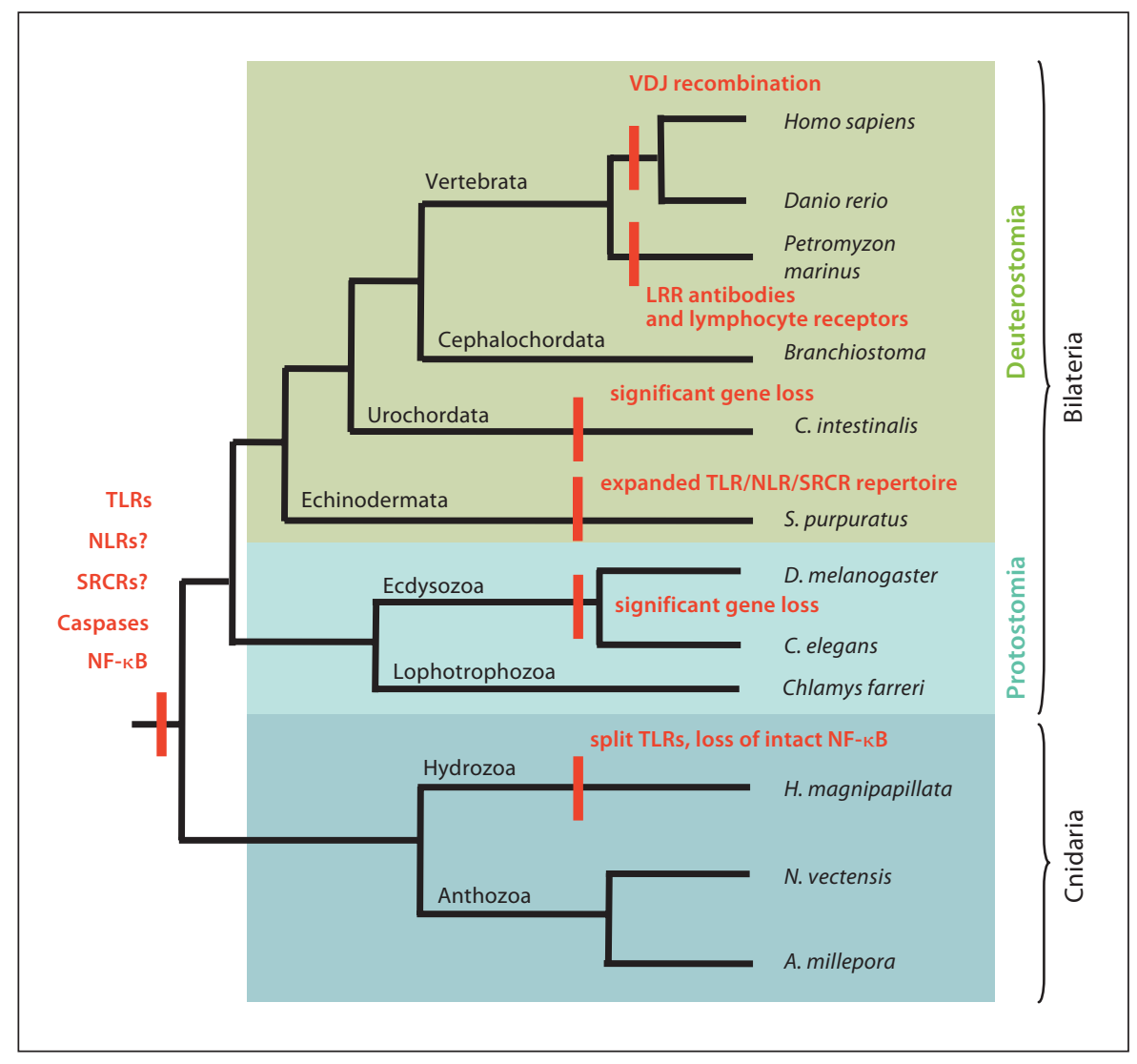

A deficient response to infections has been described as a hallmark of human aging and is among the major mortality factors in elderly people. For a long time this was mainly attributed to a deregulation of the adaptive immune system resulting in reduced immunoglobulin secretion, a decrease in $B$ cell numbers and a diminished apoptotic clearance rate of peripheral blood lymphocytes $[78,79]$. The process has been called 'immunosenescence', and the dysfunction of the adaptive immune system was thought to result from the general decline in repair and proliferation capacity of the high-aged organism [80]. We could recently demonstrate that human aging is also accompanied by complex changes of innate immune mechanisms at epithelial barriers [81]. This included not only a diminished expression of recognition molecules (both TLRs and NLRs), but also a downregulation of molecules involved in negative feedback loops (e.g., SARM1) and an augmentation of inflammation processes in the elderly. It may be hypothesized that the innate immune system has evolved to quickly control pathogens, and therefore, efficient induction of proinflammatory pathways via innate immune receptors is a necessary and important component of a host's defense mechanism early in life and in adulthood. However, it may become detrimental later in life as the overproduction of inflammatory molecules together with the decline in pathogen recognition contributes as 'inflammaging' to age-related diseases. Investigating the innate immune system and its change with age in long-lived marine invertebrates like the ocean quahog $A$. islandica or potentially immortal cnidarians may help to gain insight into mechanisms responsible for sustained and effective immune responses despite high age.

\section{Future Prospect or What Can We Learn from Invertebrate Immunity for Emerging Human Chronic Inflammatory Diseases?}

The pivotal role of NLRs, TLRs and SRCRs for the physiological immune response is paralleled by a remarkable series of association findings of polymorphisms in the cognate genes with human chronic inflammatory diseases of epithelial barrier organs. Polygenic diseases 
associated with loss-of-function variations in NLRs, TLRs and SRCRs include Crohn disease (NLR, TLR and SRCR), atopic disease and asthma (NLR and TLR), which are characterized by chronic relapsing-remitting inflammation of barrier organs (intestine, lung, skin). A suggestive association of epithelial cancer entities (breast and colonic carcinoma) with germline mutations in NOD2 and NOD1 supports the hypothesis that chronic inflammation induced by epithelial barrier dysfunction significantly contributes to the etiology of malignant diseases.

Most chronic inflammatory diseases have seen a steep rise in incidence over the last 100 years; e.g., Crohn disease was essentially unknown before the 1930s and it was thus hypothesized that environmental factors and changes in lifestyle conditions (e.g., nutrition or hygiene) in modern industrial societies are key pathophysiological triggers. Evidence has been obtained that the inappropriate immune responses observed in inflammatory barrier disorders are driven by the resident microbiota and their metabolic structure $[82,83]$. In contrast to the short history of this class of diseases, most of the genetic profiles conferring risk have arisen some 40,000 years ago [84]. It is unlikely that this genetic variability would have been conserved over such a long period of time without any evolutionary pressure favoring it. It is thus tempting to speculate that the specific sequence variability may have had protective function in the past and only recently has become a risk factor under today's living conditions [2].
The present insights into the evolutionary origins of the innate immune system in aquatic invertebrates (fig. 2) may prove to be especially useful to understand how selective pressures form genetic diversity and sequence variability to cope with different immune challenges. The advent of novel ultra-fast sequencing technologies will allow building comparative single nucleotide polymorphism maps of innate immune receptors together with an inventory of the associated microbiota in different populations of cosmopolitan invertebrate species to describe the interaction between barrier and environment. Dissecting the primordial cellular programs of innate immunity, the 'Ur-defensome', in simple eumetazoans is alleviated through transgenic technologies allowing for a stable genetic manipulation of these animals under laboratory conditions. Early branching metazoans as novel animal models may contribute to the emerging concept of evolutionary medicine in order to identify novel targets for therapeutic augmentation of barrier function and epithelial drug delivery.

\section{Acknowledgements}

Grants were received from the BMBF Nationales Genomforschungsnetz (www.ngfn.de), Deutsche Forschungsgemeinschaft (SFB415 and 617) and the Clusters of Excellence 'The Future Ocean' and 'Inflammation at Interfaces'.

\section{References}

1 Rosenberg E, Koren O, Reshef L, Efrony R, Zilber-Rosenberg I: The role of microorganisms in coral health, disease and evolution. Nat Rev Microbiol 2007;5:355-362.

-2 Schreiber S, Rosenstiel P, Albrecht M, Hampe J, Krawczak M: Genetics of Crohn disease, an archetypal inflammatory barrier disease. Nat Rev Genet 2005;6:376-388.

3 Takeda K, Kaisho T, Akira S: Toll-like receptors. Annu Rev Immunol 2003;21:335-376.

-4 Inohara N, Chamaillard M, McDonald C, Nunez G: NOD-LRR proteins: role in hostmicrobial interactions and inflammatory disease. Annu Rev Biochem 2005;74:355383.

5 Sarrias MR, Gronlund J, Padilla O, Madsen J, Holmskov U, Lozano F: The scavenger receptor cysteine-rich (SRCR) domain: an ancient and highly conserved protein module of the innate immune system. Crit Rev Immunol 2004;24:1-37.

\footnotetext{
6 Chisholm ST, Coaker G, Day B, Staskawicz BJ: Host-microbe interactions: shaping the evolution of the plant immune response. Cell 2006;124:803-814.

7 Hashimoto C, Hudson KL, Anderson KV: The Toll gene of Drosophila, required for dorsal-ventral embryonic polarity, appears to encode a transmembrane protein. Cell 1988;52:269-279.

8 Lemaitre B, Nicolas E, Michaut L, Reichhart JM, Hoffmann JA: The dorsoventral regulatory gene cassette spätzle/Toll/cactus controls the potent antifungal response in Drosophila adults. Cell 1996;86:973-983.

\$9 Janeway CA Jr, Medzhitov R: Innate immune recognition. Annu Rev Immunol 2002;20: 197-216.

10 Rast JP, Smith LC, Loza-Coll M, Hibino T, Litman GW: Genomic insights into the immune system of the sea urchin. Science 2006; 314:952-956.
}

11 Sodergren E, Weinstock GM, Davidson EH, Cameron RA, Gibbs RA, Angerer RC, Angerer LM, Arnone MI, Burgess DR, Burke RD, Coffman JA, Dean M, et al: The genome of the sea urchin Strongylocentrotus purpuratus. Science 2006;314:941-952.

12 Qiu L, Song L, Xu W, Ni D, Yu Y: Molecular cloning and expression of a Toll receptor gene homologue from Zhikong Scallop, Chlamys farreri. Fish Shellfish Immunol 2007;22:451-466.

13 Rast JP, Messier-Solek C: Marine invertebrate genome sequences and our evolving understanding of animal immunity. Biol Bull 2008;214:274-283.

14 Hibino T, Loza-Coll M, Messier C, Majeske AJ, Cohen AH, Terwilliger DP, Buckley KM, Brockton V, Nair SV, Berney K, Fugmann SD, Anderson MK, Pancer Z, Cameron RA, Smith LC, Rast JP: The immune gene repertoire encoded in the purple sea urchin genome. Dev Biol 2006;300:349-365. 
15 Wiens M, Korzhev M, Perovic-Ottstadt S, Luthringer B, Brandt D, Klein S, Muller WE: Toll-like receptors are part of the innate immune defense system of sponges (Demospongiae: Porifera). Mol Biol Evol 2007;24: 792-804.

16 Hemmrich G, Miller DJ, Bosch TC: The evolution of immunity: a low-life perspective. Trends Immunol 2007;28:449-454.

-17 Miller DJ, Hemmrich G, Ball EE, Hayward DC, Khalturin K, Funayama N, Agata K, Bosch TC: The innate immune repertoire in cnidaria - ancestral complexity and stochastic gene loss. Genome Biol 2007;8:R59.

-18 Bosch TC, Augustin R, Anton-Erxleben F, Fraune S, Hemmrich G, Zill H, Rosenstiel P, Jacobs G, Schreiber S, Leippe M, Stanisak M, Grotzinger J, Jung S, Podschun R, Bartels J, Harder J, Schroder JM: Uncovering the evolutionary history of innate immunity: the simple metazoan Hydra uses epithelial cells for host defence. Dev Comp Immunol 2009; 33:559-569.

-19 Tschopp J, Martinon F, Burns K: NALPs: a novel protein family involved in inflammation. Nat Rev Mol Cell Biol 2003;4:95-104.

-20 Ogura Y, Inohara N, Benito A, Chen FF, Yamaoka S, Nunez G: Nod2, a Nod1/Apaf-1 family member that is restricted to monocytes and activates NF-kappaB. J Biol Chem 2001;276:4812-4818.

-21 Strober W, Murray PJ, Kitani A, Watanabe T: Signalling pathways and molecular interactions of NOD1 and NOD2. Nat Rev Immunol 2006;6:9-20.

-22 Kim HM, Park BS, Kim JI, Kim SE, Lee J, Oh SC, Enkhbayar P, Matsushima N, Lee H, Yoo OJ, Lee JO: Crystal structure of the TLR4MD-2 complex with bound endotoxin antagonist Eritoran. Cell 2007;130:906-917.

$\checkmark 23$ Brodsky I, Medzhitov R: Two modes of ligand recognition by TLRs. Cell 2007;130: 979-981.

-24 Yu M, Wang H, Ding A, Golenbock DT, Latz E, Czura CJ, Fenton MJ, Tracey KJ, Yang H: HMGB1 signals through toll-like receptor (TLR) 4 and TLR2. Shock 2006;26:174-179.

-25 Tsung A, Klune JR, Zhang X, Jeyabalan G, Cao Z, Peng X, Stolz DB, Geller DA, Rosengart MR, Billiar TR: HMGB1 release induced by liver ischemia involves Toll-like receptor 4 dependent reactive oxygen species production and calcium-mediated signaling. J Exp Med 2007;204:2913-2923.

-26 Biragyn A, Ruffini PA, Leifer CA, Klyushnenkova E, Shakhov A, Chertov O, Shirakawa AK, Farber JM, Segal DM, Oppenheim JJ, Kwak LW: Toll-like receptor 4-dependent activation of dendritic cells by beta-defensin 2 . Science 2002;298:1025-1029.

-27 Chamaillard M, Hashimoto M, Horie Y, Masumoto J, Qiu S, Saab L, Ogura Y, Kawasaki A, Fukase K, Kusumoto S, Valvano MA, Foster SJ, Mak TW, Nunez G, Inohara N: An essential role for NOD1 in host recognition of bacterial peptidoglycan containing diaminopimelic acid. Nat Immunol 2003;4:702-707.
28 Girardin SE, Boneca IG, Carneiro LA, Antignac A, Jehanno M, Viala J, Tedin K, Taha MK, Labigne A, Zahringer U, Coyle AJ, Di Stefano PS, Bertin J, Sansonetti PJ, Philpott DJ: Nod1 detects a unique muropeptide from gram-negative bacterial peptidoglycan. Science 2003;300:1584-1587.

29 Girardin SE, Boneca IG, Viala J, Chamail lard M, Labigne A, Thomas G, Philpott DJ, Sansonetti PJ: Nod2 is a general sensor of peptidoglycan through muramyl dipeptide (MDP) detection. J Biol Chem 2003;278: 8869-8872.

30 Inohara N, Ogura Y, Fontalba A, Gutierrez $\mathrm{O}$, Pons F, Crespo J, Fukase K, Inamura S Kusumoto S, Hashimoto M, Foster SJ, Moran AP, Fernandez-Luna JL, Nunez G: Host recognition of bacterial muramyl dipeptide mediated through NOD2. Implications for Crohn's disease. J Biol Chem 2003;278:5509_ 5512.

31 Dostert C, Petrilli V, Van Bruggen R, Steele C, Mossman BT, Tschopp J: Innate immune activation through Nalp3 inflammasome sensing of asbestos and silica. Science 2008; 320:674-677.

32 Martinon F, Agostini L, Meylan E, Tschopp J: Identification of bacterial muramyl dipeptide as activator of the NALP3/cryopyrin in flammasome. Curr Biol 2004;14:1929-1934.

33 Mariathasan S, Weiss DS, Newton K, McBride J, O’Rourke K, Roose-Girma M, Lee WP, Weinrauch Y, Monack DM, Dixit VM: Cryopyrin activates the inflammasome in response to toxins and ATP. Nature 2006; 440:228-232.

34 Martinon F, Petrilli V, Mayor A, Tardivel A, Tschopp J: Gout-associated uric acid crystals activate the NALP3 inflammasome. Nature 2006;440:237-241.

35 Kanneganti TD, Lamkanfi M, Kim YG, Chen G, Park JH, Franchi L, Vandenabeele P, Nunez G: Pannexin-1-mediated recognition of bacterial molecules activates the cryopyrin inflammasome independent of Tolllike receptor signaling. Immunity 2007;26: 433-443.

36 Ting JP, Davis BK: CATERPILLER: a novel gene family important in immunity, cell death, and diseases. Annu Rev Immunol 2005;23:387-414.

37 Rosenstiel P, Jacobs G, Till A, Schreiber S NOD-like receptors: ancient sentinels of the innate immune system. Cell Mol Life Sci 200; 65:1361-1377

38 Park HH, Lo YC, Lin SC, Wang L, Yang JK, $\mathrm{Wu} \mathrm{H}$ : The death domain superfamily in intracellular signaling of apoptosis and inflammation. Annu Rev Immunol 2007;25: 561-586.

39 Watanabe T, Kitani A, Murray PJ, Strober W: NOD2 is a negative regulator of Toll-like receptor 2-mediated T helper type 1 responses. Nat Immunol 2004;5:800-808
40 Fritz JH, Le Bourhis L, Sellge G, Magalhaes JG, Fsihi H, Kufer TA, Collins C, Viala J, Ferrero RL, Girardin SE, Philpott DJ: Nod1-mediated innate immune recognition of peptidoglycan contributes to the onset of adaptive immunity. Immunity 2007;26:445-459.

-41 Magalhaes JG, Fritz JH, Le Bourhis L, Sellge G, Travassos LH, Selvanantham T, Girardin SE, Gommerman JL, Philpott DJ: Nod2-dependent Th2 polarization of antigen-specific immunity. J Immunol 2008;181:7925-7935.

42 Rosenstiel P, Fantini M, Brautigam K, Kuhbacher T, Waetzig GH, Seegert D, Schreiber S: TNF-alpha and IFN-gamma regulate the expression of the NOD2 (CARD15) gene in human intestinal epithelial cells. Gastroenterology 2003;124:1001-1009.

-43 Hisamatsu T, Suzuki M, Reinecker HC, Nadeau WJ, McCormick BA, Podolsky DK: CARD15/NOD2 functions as an antibacterial factor in human intestinal epithelial cells. Gastroenterology 2003;124:993-1000.

44 Hisamatsu T, Suzuki M, Podolsky DK: Interferon-gamma augments CARD4/NOD1 gene and protein expression through interferon regulatory factor-1 in intestinal epithelial cells. J Biol Chem 2003;278:3296232968.

45 Kim JG, Lee SJ, Kagnoff MF: Nod1 is an essential signal transducer in intestinal epithelial cells infected with bacteria that avoid recognition by toll-like receptors. Infect Immun 2004;72:1487-1495.

46 Rosenstiel P, Hellmig S, Hampe J, Ott S, Till A, Fischbach W, Sahly H, Lucius R, Folsch UR, Philpott D, Schreiber S: Influence of polymorphisms in the NOD1/CARD4 and NOD2/CARD15 genes on the clinical outcome of Helicobacter pylori infection. Cell Microbiol 2006;8:1188-1198.

47 Viala J, Chaput C, Boneca IG, Cardona A, Girardin SE, Moran AP, Athman R, Memet S, Huerre MR, Coyle AJ, Distefano PS, Sansonetti PJ, Labigne A, Bertin J, Philpott DJ, Ferrero RL: Nod1 responds to peptidoglycan delivered by the Helicobacter pylori cag pathogenicity island. Nat Immunol 2004;5: 1166-1174.

48 Wehkamp J, Salzman NH, Porter E, Nuding S, Weichenthal M, Petras RE, Shen B, Schaeffeler E, Schwab M, Linzmeier R, Feathers RW, Chu H, Lima H Jr, Fellermann K, Ganz T, Stange EF, Bevins CL: Reduced Paneth cell alpha-defensins in ileal Crohn's disease. Proc Natl Acad Sci USA 2005;102:1812918134.

49 Wehkamp J, Harder J, Weichenthal M, Schwab M, Schaffeler E, Schlee M, Herrlinger KR, Stallmach A, Noack F, Fritz P, Schroder JM, Bevins CL, Fellermann K, Stange EF: NOD2 (CARD15) mutations in Crohn's disease are associated with diminished mucosal alpha-defensin expression. Gut 2004;53:1658-1664. 
50 Kobayashi KS, Chamaillard M, Ogura Y, Henegariu O, Inohara N, Nunez G, Flavell RA: Nod2-dependent regulation of innate and adaptive immunity in the intestinal tract. Science 2005;307:731-734.

- 51 Freeman M, Ashkenas J, Rees DJ, Kingsley DM, Copeland NG, Jenkins NA, Krieger M: An ancient, highly conserved family of cysteine-rich protein domains revealed by cloning type I and type II murine macrophage scavenger receptors. Proc Natl Acad Sci USA 1990;87:8810-8814.

- 52 Bikker FJ, Ligtenberg AJ, End C, Renner M, Blaich S, Lyer S, Wittig R, van't Hof W, Veerman EC, Nazmi K, de Blieck-Hogervorst JM, Kioschis P, Nieuw Amerongen AV, Poustka A, Mollenhauer J: Bacteria binding by DMBT1/SAG/gp-340 is confined to the VEVLXXXXW motif in its scavenger receptor cysteine-rich domains. J Biol Chem 2004; 279:47699-47703.

-53 Rosenstiel P, Sina C, End C, Renner M, Lyer S, Till A, Hellmig S, Nikolaus S, Folsch UR, Helmke B, Autschbach F, Schirmacher P, Kioschis P, Hafner M, Poustka A, Mollenhauer J, Schreiber S: Regulation of DMBT1 via NOD2 and TLR4 in intestinal epithelial cells modulates bacterial recognition and invasion. J Immunol 2007;178:8203-8211.

-54 Pancer Z, Rast JP, Davidson EH: Origins of immunity: transcription factors and homologues of effector genes of the vertebrate immune system expressed in sea urchin coelomocytes. Immunogenetics 1999;49:773786.

-55 Pancer Z: Dynamic expression of multiple scavenger receptor cysteine-rich genes in coelomocytes of the purple sea urchin. Proc Natl Acad Sci USA 2000;97:13156-13161.

56 Pancer Z: Individual-specific repertoires of immune cells SRCR receptors in the purple sea urchin (S. purpuratus). Adv Exp Med Biol 2001;484:31-40.

57 Steindler L, Schuster S, Ilan M, Avni A, Cerrano C, Beer S: Differential gene expression in a marine sponge in relation to its symbiotic state. Mar Biotechnol (NY) 2007;9:543549.

58 Hooper LV, Gordon JI: Commensal hostbacterial relationships in the gut. Science 2001;292:1115-1118.

59 Macpherson AJ, Harris NL: Interactions between commensal intestinal bacteria and the immune system. Nat Rev Immunol 2004;4: 478-485.

60 Rakoff-Nahoum S, Paglino J, Eslami-Varzaneh F, Edberg S, Medzhitov R: Recognition of commensal microflora by toll-like receptors is required for intestinal homeostasis. Cell 2004;118:229-241.
61 Alley CD, Kiyono H, McGhee JR: Murine bone marrow IgA responses to orally administered sheep erythrocytes. J Immunol 1986; 136:4414-4419.

62 Fanaro S, Chierici R, Guerrini P, Vigi V: Intestinal microflora in early infancy: composition and development. Acta Paediatr Suppl 2003;91:48-55.

63 Dai D, Walker WA: Protective nutrients and bacterial colonization in the immature human gut. Adv Pediatr 1999;46:353-382.

64 Walker WA: Role of nutrients and bacterial colonization in the development of intestinal host defense. J Pediatr Gastroenterol Nutr 2000;30:S2-S7.

65 Smith S, Vaughan EE, De Vos WM: Quorum sensing within the gut. Microbial Ecol Health Dis 2000;2(suppl):81-92.

66 Falcao JP, Sharp F, Sperandio V: Cell-to-cell signaling in intestinal pathogens. Curr Issues Intest Microbiol 2004;5:9-17.

67 Mazmanian SK, Kasper DL: The love-hate relationship between bacterial polysaccharides and the host immune system. Nat Rev Immunol 2006;6:849-858.

68 Mazmanian SK: Capsular polysaccharides of symbiotic bacteria modulate immune responses during experimental colitis. J Pediatr Gastroenterol Nutr 2008;46(suppl 1): E11-E12.

69 Ruby EG, McFall-Ngai MJ: A squid that glows in the night: development of an animal-bacterial mutualism. J Bacteriol 1992; 174:4865-4870.

70 Nyholm SV, McFall-Ngai MJ: Dominance of Vibrio fischeri in secreted mucus outside the light organ of Euprymna scolopes: the first site of symbiont specificity. Appl Environ Microbiol 2003;69:3932-3937.

71 Koropatnick TA, Engle JT, Apicella MA, Stabb EV, Goldman WE, McFall-Ngai MJ: Microbial factor-mediated development in a host-bacterial mutualism. Science 2004;306: 1186-1188.

72 Magalhaes JG, Philpott DJ, Nahori MA, Jehanno M, Fritz J, Bourhis LL, Viala J, Hugot JP, Giovannini M, Bertin J, Lepoivre M, Mengin-Lecreulx D, Sansonetti PJ, Girardin SE: Murine Nod1 but not its human orthologue mediates innate immune detection of tracheal cytotoxin. EMBO Rep 2005;6:12011207.

73 Rahat M, Dimentman C: Cultivation of bacteria-free Hydra viridis: missing budding factor in nonsymbiotic hydra. Science 1982 ; 216:67-68.
4 Ziuganov VV: Arctic and southern freshwater pearl mussel Margaritifera margaritifera with long and short life span as a model system for testing longevity mechanisms. Adv Gerontol 2004;14:21-30.

-75 Taylor AC, Brand AR: A comparative study of the respiratory responses of the bivalves Arctica islandica (L.) and Mytilus edulis L. to declining oxygen tension. Proc R Soc Lond B Biol Sci 1975;190:443-456.

-76 Abele D, Strahl J, Brey T, Philipp EE: Imperceptible senescence: ageing in the ocean quahog Arctica islandica. Free Radic Res 2008; 42:474-480.

-77 Sauvage C, Bierne N, Lapegue S, Boudry P: Single nucleotide polymorphisms and their relationship to codon usage bias in the $\mathrm{Pa}$ cific oyster Crassostrea gigas. Gene 2007;406: 13-22.

78 Franceschi C, Bonafe M, Valensin S, Olivieri F, De Luca M, Ottaviani E, De Benedictis G: Inflamm-aging. An evolutionary perspective on immunosenescence. Ann NY Acad Sci 2000;908:244-254.

79 Franceschi C, Olivieri F, Marchegiani F, Cardelli M, Cavallone L, Capri M, Salvioli S, Valensin S, De Benedictis G, Di Iorio A, Caruso $\mathrm{C}$, Paolisso G, Monti D: Genes involved in immune response/inflammation, IGF1/ insulin pathway and response to oxidative stress play a major role in the genetics of human longevity: the lesson of centenarians. Mech Ageing Dev 2005;126:351-361.

80 Walford RL: The Immunologic Theory of Aging. Copenhagen, Munksgaard, 1969.

-81 Rosenstiel P, Derer S, Till A, Hasler R, Eberstein H, Bewig B, Nikolaus S, Nebel A, Schreiber S: Systematic expression profiling of innate immune genes defines a complex pattern of immunosenescence in peripheral and intestinal leukocytes. Genes Immun 2008;9:103-114.

-82 Gent AE, Hellier MD, Grace RH, Swarbrick ET, Coggon D: Inflammatory bowel disease and domestic hygiene in infancy. Lancet 1994;343:766-767.

83 Backhed F, Ley RE, Sonnenburg JL, Peterson DA, Gordon JI: Host-bacterial mutualism in the human intestine. Science 2005;307:19151920

-84 Croucher PJ, Mascheretti S, Hampe J, Huse K, Frenzel H, Stoll M, Lu T, Nikolaus S, Yang SK, Krawczak M, Kim WH, Schreiber S: Haplotype structure and association to Crohn's disease of CARD15 mutations in two ethnically divergent populations. Eur J Hum Genet 2003;11:6-16. 